\title{
DEVELOPING GEOSPATIAL SCIENTISTS - USING STUDENTS AS PARTNERS IN DRONE RESEARCH
}

\author{
T. McKee, L. Hashemi-Beni
}

Department of Geomatics and Built Environment, North Carolina Agricultural and Technical

State University, Greensboro, North Carolina -tlmckee@aggies.ncat.edu - lhashemibeni@ncat.edu

KEY WORDS: Geospatial, Students, Research, Data, GIS, Drone, Education, STEM

\begin{abstract}
:
The U.S. Department of Labor Occupational Outlook Handbook predicts geospatial careers to increase much faster than average (15\%) from 2018 to 2028 with no additional on-the-job training expected. Geospatial professionals can assist in promoting these career opportunities by mentoring high school students through real-world and transferable-skill building activities. The aim is to enhance students' awareness and stimulate their interest towards STEM education and careers, especially in geospatial data analytics. This area of study incorporates a variety of modern-day tools for analyzing and mapping the Earth. The technology used offers a radically different way in which geospatial scientist produce and use the geospatial information required to manage a large variety of communities and industries.
\end{abstract}

\section{INTRODUCTION}

Geospatial Science is an area of study that incorporates a variety of modern-day tools for analyzing and mapping the Earth (American Association for the Advancement of Science, 2020). It includes the development and applications of traditional geospatial technologies, such as geographic information systems (GISs), global positioning systems (GPSs) and remote sensing (RS) (National Research Council, 2013) as well as continuously evolving and interdisciplinary technologies such as drones, miniature sensors, real-time spatiotemporal data analytics, crowdsourcing, geolocation, and wireless infrastructure (Federal Geographic Data Committee, 2016).

These technologies individually present dynamic challenges. The workforce required to administer, deploy and display our technologies cannot be uniformly trained (Hammond, et al., 2019). Traditional K-12 learning environments would be ideal but these environments are not designed to specialize in geospatial learning because the educational landscape varies across US school systems, such as how much geospatial content is taught, how the content is structured, and how the content emphasizes scientific careers (Petcovic, et al., 2018). Additionally, it is estimated that only $3 \%$ of secondary educators are formally trained in a geospatial field of study (American Geoscience Institutue, 2010). Therefore, geospatial scientists must be engaged in mentoring and performing discipline specific educational research to determine best practices for training future geospatial scientists on these continuously evolving technologies. Accordingly, the following research aims to orient high school students to geographic information system mapping and drone research using an applied data literacy approach.

For the purpose of this research, data literacy is defined as the ability to plan for, document, analyze and visualize data. Geospatial curriculum tasks will be guided by the U.S. Department of Labor, Employment and Training Administration's Geospatial Technology Competency Model
(GTCM) (U.S. Department of Labor, Employment and Training Administration, 2020). The GTCM is a 9-tier pyramid that illustrates industry, academic, workplace and personal competencies that geospatial professionals should seek to acquire. The specific knowledge, skills, and abilities recommended for success are listed for each individual competency. The GTCM is designed to assist users with a variety of objectives, such as geospatial curriculum development, geospatial workforce needs and career readiness goals. Additionally, the model provides useful tools, such as a pre- and post- geospatial skills gap assessment to assist with curriculum or training alignment.

K-12 data literacy approaches are also supported by the National Academies of Sciences, Engineering and Medicine in a recent report: Science and Engineering for Grades 6-12: Investigation and Design at the Center (2019), which states that students in grades 6-12 gain knowledge and reasoning abilities by manipulating and visualizing data they have collected themselves versus data obtained from secondary sources (National Academies of Sciences, Engineering, and Medicine, 2019). They acknowledge that the ability to work with data is at the core of science and engineering. Therefore, students should have in-depth opportunities to develop a data skillset. This issue is critical for STEM students because prior learning experiences shape student identities, knowledge, attitude, and understandings in future learning environments (Roberts, et al., 2018). Out-ofschool programs and informal experiences that engage and train students using real-world data drawn from their local environment connect students to their communities and may assist in increasing the number of geospatial scientists in the US workforce.

The remainder of the article is outlined in the following sections: Developing Geospatial Scientists, Theoretical Framework, Methodology, Geospatial Summer Program Characteristics and Future Recommendations. 


\subsection{Developing Geospatial Scientists}

What is often not considered by geospatial professionals is who among us will be responsible for mentoring and training future geospatial scientists using authentic real-world research experiences that incorporate relevant geospatial technologies (Huntoon, et al., 2005). It is a fallacy to make an assumption that K-12 science educators alone will do this; they face many challenges within their own field of study.

In general, science educators in K-12 environments face a range of administrative challenges; from how a class is evaluated to the time allotted for instruction (Ayotte-Beaudet, et al., 2017). Science educators are further limited by factors, such as the assumption that geospatial concepts are of less rigor, lack of access to geospatial technology, training, and lack of financial support for geospatial programs (Orion, 2019). Osborne et al. (2020) conducted research that suggested even geospatial educators may lack interest or even knowledge of how geospatial technology is related to their own high school geography curriculum (Osborne, et al., 2020). This lack of educator exposure to geospatial technology, workshops, and coursework can negatively influence $6^{\text {th }}$ thru $12^{\text {th }}$ grade student career aspirations. For example, the number of undergraduate students pursuing geoscience degrees has not significantly changed since 2012 (Keane, 2018). Additionally, 50\% of students entering STEM fields at the undergraduate level do not finish (Seymour \& Hunter, 2019).

The preparation of students during $6^{\text {th }}$ through $12^{\text {th }}$ grade is a contributing factor for success. Students must plan and establish an academic schedule that permits them to transition towards science careers prior to their $11^{\text {th }}$ or $12^{\text {th }}$ grade of high school because K-12 science tracks are often designed to begin in $9^{\text {th }}$ grade. Hands-on opportunities and geospatial engagement at local levels will be key to bridging this academic disconnect.

\subsection{Informal Learning Environments}

With so many limitations on traditional K-12 education, informal learning environments represent an optimum avenue to expose students to geospatial research and activities. This approach is critical because research has shown that students exposed to careers at an early age are more aware of what skills they need to develop to enter in to a said career (Cagle, et al., 2018). Unfortunately, geospatial careers are often not presented as an option

To promote the progress of geospatial science, geospatial scientists must be committed to engaging in participatory research with students with an understanding that the next generation of geoscientists are being mentored and trained (Hawthorne \& Jarrett, 2018). Students engaged in mentored experiences are free to offer new perspectives on geospatial research. Additionally, Historically Black Colleges and Universities (HBCUs) are traditionally positioned to be key partners for recruiting, training and mentoring underrepresented geoscientists; especially within K-12 academic levels and informal environments (Archer, et al., 2018).

\section{THEORETICAL FRAMEWORK}

The theoretical framework for the study is based on how students learn in informal environments (National Research Council, 2009). Students are not simply learning conceptual knowledge and scientific skills; they are learning the culture of science, understanding how it blends with their daily life, how it is relevant to them and how it requires interactive collaboration (Fenichel \& Schweingruber, 2010). Informal learning becomes an extension of their environment and a source of personal enjoyment (i.e. watching TV, participating in a program, volunteering, visiting museums).

\section{METHODOLOGY}

Program implementation was initially planned as a one-week day summer program with high school students on a university campus. However, due to COVID-19, the program is transitioning to an online learning environment. Therefore, the program itself will be discussed briefly.

\subsection{Pre-Program Tasks}

Students were scheduled to complete pre-program tasks designed to provide research context and background information Examples include but are not limited to online questionnaires, videos, getting-to-know each other activities and program registration.

\subsection{Recruitment}

Eighteen high school students from Guildford County, North Carolina were recruited to participate in the GIS \& Drones Program. Recruitment efforts were assisted through previously established university and K-12 community partnerships.

\subsection{Program Implementation}

Program implementation will focus on two major themes: 1) GIS Mapping and 2) Drone Data Processing and Visualization. Students will build GIS and Drone research-based portfolios. The portfolios serve as artifacts of what students have learned and accomplished. Each student will select up to two (2) portfolio documents to present at the end of the program. Students are required to include a minimum of six documents in their final portfolio. Each document aligns with and reflects one major task.

\subsection{Evaluation}

Evaluation will occur across three (3) levels: students, programs, and parents. A logic model will guide the evaluation (Montano, 2016). Evaluations will consist of pre and post program surveys, focus group discussions, instructor observations, and student portfolios. A pilot study of all surveys will be conducted to make necessary revisions to the interview instruments and test survey administration. 


\section{FUTURE RECOMENDATIONS}

\subsection{Incorporate Relevant Data Sources}

The Geospatial Data Act of 2018 will increase public and private access to geospatial data (The Federal Geographic Data Committee, 2020). Geospatial data is continuously being made available for public and private use. The inclusion of this new data at local and regional levels has the opportunity to produce better local-level mapping applications. For example, new geospatial data will be included with GeoPlatform.gov, the National Aeronautics and Space Administration, and the US Department of Defense. Additionally, with the current issue of COVID-19 throughout the US and globally, more options are opening up for students to collect and apply geospatial data

\subsection{Integrate Advanced-Level Activities}

As geospatial scientists, we know our field of study best. Therefore, we are equipped to expose students to advanced-level geospatial technologies that may not be offered through traditional K-12 systems. For example, once students are at ease using drone software, opportunities to utilize advanced-level drones, such as drones that follow the terrain like a missile or follow the user, may be explored with students and applied to exploratory research applications (e.g., emergency management, agriculture, food insecurity)

\subsection{Discipline Specific Educational Research}

Discipline specific educational research and K-12 student engagement are a natural fit. Students may provide collaborative insight, unexpected feedback and suggest technological applications that have never been considered or presented through formal research avenues. Understanding these variabilities are critical for geospatial science and education that extends beyond educational classrooms. Ultimately, every geoscientist's journey begins with exposure and opportunity because it is impossible for a student to identify with and express in interest in a field of study in which they have never shown as existing.

\subsection{Inclusion of Supplemental Activities}

The inclusion of supplemental activities are helpful when designed to expose students to new geospatial technologies. Supplemental activities related to the current research may be classified as research-based or relaxation-based. Researchbased topics include machine learning, agent-based modeling, simulations, smart and precision agriculture, flood management, and renewable energy siting. Relaxation-based activities include geocaching, fishing, scavenger hunts, yoga, line-dancing, and meditation.

\section{ACKNOWLEDGEMENTS}

This material is based upon work supported by Title III and the National Science Foundation under Grants \#1800768 and $\# 1832110$. Any opinions, findings, and conclusions or recommendations expressed in this material are those of the author(s) and do not necessarily reflect the views of the National Science Foundation.

\section{COMPETING INTERESTS STATEMENT}

The authors have no competing interests to declare.

\section{REFERENCES}

American Association for the Advancement of Science, 2020. What are geospatial technologies?. [Online]

Available at: https://www.aaas.org/programs/scientificresponsibility-human-rights-law/overview-geospatial-project [Accessed 1 June 2020].

American Geoscience Institutue , 2010. K-12 Teachers and Geoscience Degrees. [Online] Available at: https://www.americangeosciences.org/geoscience-currents/k12-teachers-and-geoscience-degrees

[Accessed 1 July 2020].

Archer, R. S., Davis, F., Ebanks, S. C. \& Schulterbrandt Gragg III, R. D., 2018. HBCUs Broadening Participation in Geosciences (A Journey Through InTeGrate). In: Interdisciplinary Teaching About Earth and the Environment for a Sustainable Future. AESS Interdisciplinary Environmental Studies and Sciences Series. New York City: Springer, Cham, pp. 361-378.

Ayotte-Beaudet, J., Potvin, P., Lapierre, H. \& Glackin, M., 2017. Teaching and Learning Science Outdoors in Schools' Immediate Surroundings at K-12 Levels: A Meta-Synthesis. EURASIA Journal of Mathematics Science and Technology Education, pp. 5343-5363.

Cagle, N. L., Caldwell, L. \& Garcia, R., 2018. K-12 Diversity Pathway Programs in the E-STEM Fields: A Review of Existing Programs and Summary of Perceived and Unmet Needs. Journal of STEM Education, pp. 12-18.

Federal Geographic Data Committee, 2016. Emerging Technologies and the Geospatial Landscape: A Report by the National Geospatial Advisory Committee. Available online: https://www. fgdc. gov/ngac/meetings/dec-2016/ngac-paperemerging-technologies-and-the. pdf (accessed on 16 June 2020), s.1.: s.n.

Fenichel, M. \& Schweingruber, H. A., 2010. Surrounded by Science: Learning Science in Informal Environments. Board of Science Education, Center for Education, Division of Behavioral and Social Sciences and Education, Washington, DC: The National Academies Press.

Hammond, T. et al., 2019. Shoulder to Shoulder: Teacher Professional Development and Curriculum Design and Development for Geospatial Technology Integration With Science and Social Studies Teachers. Contemporary Issues in Technology and Teacher Education, 19(2), pp. 279-301.

Hawthorne, T. L. \& Jarrett, O. S., 2018. Developing the Next Generation of CommunityBased Scholars. The Professional Geographer, pp. 291-297. 
Huntoon, J., Peach, C. \& Hopkins, J., 2005. Geoscience Education and Diversity: Vision for the Future and Strategies for Success Report of the Second Geoscience Education Working Group, Washington, DC: Nationla Science Foundation Report.

Keane, C., 2018. American Geosciences Institute. [Online] Available at:

https://www.americangeosciences.org/sites/default/files/current s/Currents-130 0.pdf [Accessed 2 July 2020].

Montano, P., 2016. A Start To Developing a Logic Model. [Online] Available at: https://www.informalscience.org/newsviews/start-developing-logic-model

National Academies of Sciences, Engineering, and Medicine, 2019. Science and Engineering for Grades 6-12: Investigation and Design at the Center, Washington, DC.: The National Academies Press.

National Research Council, 2009. Learning Science in Informal Environments: People, Places, and Pursuits. Washington: DC: THe National Academies Press.

National Research Council, 2013. Future U.S. Workforce for Geospatial Intelligence, Washington, DC: The National Academies Press.

Orion, N., 2019. The future challenge of Earth science education research. Disciplinary and Interdisciplinary Science Education Research, pp. 1-8.
Osborne, Z. M., van de Gevel, S. L., Eck, M. A. \& Sugg, M., 2020. An Assessment of Geospatial Technology Integration in K-12 Education. Journal of Geography, pp. 12-21.

Petcovic, H. L. et al., 2018. Research on Elementary, Middle, and Secondary Earth and Space Sciences Teacher Education. In: A Community Framework for Geoscience Education Research. Northfield: National Association of Geoscience Teachers, pp. 35-48.

Roberts, T. et al., 2018. Students' perceptions of STEM learning after participating in a summer informal learning experience. International Jouranl of STEM Education, 5(35), pp. 1-14.

Seymour, E. \& Hunter, A.-B., 2019. Talking about Leaving Revisited: Persistence, Relocation, and Loss in Undergraduate STEM Education. Chan,, Switzerland: Springer.

The Federal Geographic Data Committee, 2020. Geospatial Data Act of 2018. [Online] Available at: https://www.fgdc.gov/gda[Accessed 15 June 2020].

U.S. Department of Labor, Employment and Training Administration, 2020. Geospatial Technology Competency Model. [Online]Available at: https://www.careeronestop.org/CompetencyModel/competency -models/geospatial-technology.aspx [Accessed 7 June 2020]. 